ISSN: 2578-3335 (Print) 2578-3343 (Online)

\title{
The Ten Commandments of the Residency Interview
}

Warren R. Heymann MD

Cooper Medical School of Rowan University, heymann-warren@cooperhealth.edu

Annette Reboli MD

Cooper Medical School of Rowan University, reboli@rowan.edu

Cooper Rowan Medical Journal: https://rdw.rowan.edu/crjcsm

Would you like to be a reviewer? Please fill in this short form to express your interest.

\section{Recommended Citation}

Heymann, Warren R. MD and Reboli, Annette MD (2019) "The Ten Commandments of the Residency Interview," Cooper Rowan Medical Journal: Vol. 1 : Iss. 1 , Article 7.

DOI: 10.31986/issn.2578-3343_vol1iss1.7

Available at: https://rdw.rowan.edu/crjcsm/vol1/iss1/7

\section{(c) (i)}

This work is licensed under a Creative Commons Attribution 4.0 License.

This Medical Musings is brought to you for free and open access by the Rowan University Journals at Rowan Digital Works. It has been accepted for inclusion in Cooper Rowan Medical Journal by an authorized editor of Rowan Digital Works. For more information, please contact brush@rowan.edu. 


\section{The Ten Commandments of the Residency Interview}




\title{
The Ten Commandments of the Residency Interview
}

\author{
Warren Heymann ${ }^{1}$ \& Annette Reboli ${ }^{2}$ \\ ${ }^{1}$ Suite 306, Cooper Medical School of Rowan University, 100 Brick Road, Marlton, 08053, NJ, USA. \\ Tel.: 856-596-0111, Fax: 856-596-7194 \\ ${ }^{2}$ Cooper Medical School of Rowan University, 401 Broadway, Camden, 08103, NJ, USA
}

Medical school is a stressful enterprise. The days of getting a medical degree and knowing that you will practice in any specialty you desire have become folklore of the past. The number of residency positions available to medical school graduates has not kept pace with the increased number of new medical schools and students. Every discipline is now competitive but the problem is particularly acute for the most competitive programs, such as plastic surgery, orthopedics, otolaryngology, and dermatology.

Twenty years ago, one of us (WRH) offered advice to aspiring dermatology residency applicants. ${ }^{1}$ One of us (AR) thought the advice was so useful that she suggested it be made more generic so that it could be applied to any discipline. Although the sentiments expressed have not changed, the competitive nature of the application process has become exponentially more intense. Many candidates now have board scores bordering on perfection, a gap year of research resulting in first-author publications rivaling those applying for promotion to associate professor, and global extracurricular efforts that would make the Peace Corps proud. As it becomes increasingly difficult to differentiate these stellar applicants on paper (excuse us, computer screen), the interview is of paramount importance in choosing an applicant who will be the right fit for any given program.

Unquestionably, truly worthy residency applicants may fail to match despite doing everything "right". ${ }^{2}$ However, every year there are a handful of applicants who we do not rank in their desired specialty, based solely on a poor interview performance.

The type of interview may vary from program to program. ${ }^{3,4} \mathrm{With}$ the understanding that interviews may be structured (the person or team conducting the interview utilizes a standardized set of questions that focuses on the candidate's experiences and abilities) or unstructured (the approach is more conversational and unscripted), and the caveat that criteria defining an outstanding interview are entirely subjective, we believe that adherence to this list of "Ten Commandments" for the interviewee would be advantageous for most applicants.

I. Be yourself. Be genuine. To do otherwise is a disservice to the interviewer, but, moreimportantly, yourself. A skilled interviewer can sniff out insincerity like a hound dog trained to find narcotics at 
Terminal A of the Philadelphia International Airport. The concept of an ideal resident is an abstraction and myth. We would gladly accept learning that you ultimately wish to be in private practice rather than an academic path, if you are only saying the latter because you think that is what we want to hear. You cannot anticipate expectations, likes, or biases of the interviewer across the table from you; therefore, it is beneficial to convey precisely who you really are.

II. Smile. It will help you relax. A warm smile creates an inviting atmosphere, alleviating pressure on yourself and the interviewer. Analogize the situation to going on a date - most people enjoy the ambiance of levity and repartee but don' t overdo it.

III. Know your curriculum vitae-cold. During a 15-minute interview, the last thing you want to do is embarrass yourself because you could not answer the most basic questions about your accomplishments. Similarly, don' t embellish your accomplishments, skills, or expertise. (An example is claiming fluency in a foreign language when you aren' t. You will lose credibility and a position if the interviewer speaks fluently and you can't respond.) Have a short “elevator speech ” ready about your medical school 's curriculum and special experiences that you had.

IV. Adhere to the ethics of the sage Hillel: "If I am not for myself, who will be for me? But if I am only for myself, who am I? If not now, when?" Being a resident is a complicated affair. Certainly, you want a superlative educational experience that will set the foundation for a productive career, but it is not just about you. Convey what skill set(s) you can bring to the program to enhance the academic environment for your teachers and peers. Program directors look for three major features in potential applicants. Will they be competent, conscientious, and collegial junior colleagues?

V.Look beyond the program's website. Applicants are frequently asked what they know about the residency. Usually, the response is, "I looked at your website". Sometimes the abysmal replyis: "Nothing. I just wanted to come and get the feel of the place." With that answer, one has to ask if this person will go the proverbial extra mile in researching a patient's illness, or will they just take a cursory look at a text book, at best? Compare those answers to applicants who pull articles published by our faculty and have made an effort to speak with others about what our program has to offer.

VI. Ask about what makes the program special. We always ask applicants if they have any questions for us. Incredulously, some will say “no.” Please ask meaningful questions about our program, but there is one question we would suggest avoiding - "What are your program's weaknesses?" Every residency has its strengths and challenges, with room for improvement, yet what one might consider a deficiency, another applicant might view as desirable. For example, if you want to spend six months of bench research during our dermatology residency, our program is not for you. If you want a small, intimate, clinically oriented program with an urban experience, you struck gold. 
VII. Ask faculty about their research interests. The faculty member will be delighted, and you will be stimulated. Questions like that go much further than asking how may hours of didactic hours you receive a week. Leave those queries for the current residents.

VIII. Inquire about the past, present, and future of the program. You will learn a great deal about the residency if you know something about its history, what paths the graduates have taken, and where the program is headed. This is helpful for you to assess if you want to be a part of the program's future and help shape it.

IX. All aspects of the interview process are formal—including phone conversations with the assistant and any meals with the current residents. Be gracious to everyone you encounter - not just the faculty and residents. It is not uncommon for applicants to be invited to dinner with current residents the night before the interviews. A first-year resident might be the applicant's primary contact. While not an interview, your attitude and behavior will certainly be noted and considered when it comes time to develop the match list. The last person a program wants to match is Eddie Haskell (an insincere sycophant from the popular 60's television show Leave It to Beaver) who was one person to parents and another to his peers. Googleit. $\mathbf{X}$. Write a thank you note - if you think it is deserved - and write it by hand. It may be years since you picked up a pen and paper, but this is the time to do so. Perhaps this concept is generational, but we believe that a hand-written note has far greater impact than an email or text.

As the application season for 2020 gets into gear, we hope that all qualified applicants get invited to several interviews. Following these Ten Commandments will not guarantee a successful match, but they will increase the odds. One final word of advice - practice before you go. A study of 59 student pharmacists applying for a residency participated in a mock interview session. Those participants completing the post-session survey $(n=52)$ unanimously reported an enhanced confidence in interviewing skills following the mock interview. ${ }^{5}$ The internet also has an abundance of lists of questions that are frequently asked during residency interviews.

Best wishes for success in the interview process and in the Match!

\section{REFERENCES}

1. Advice for the dermatology residency applicant. Arch Dermatol. 2000;136:123-127.

2. Wr Heymann. Dermatology Match Day: The ecstasy and the agony. Skinmed. ; in press.

3. Martin M, Salzberg L. Resident characteristics to evaluate during recruitment and interview. Educ Prim Care. 2017;28:81-85. 
4. Hughes B D, Perone J A, Cummins C B, Sommerhalder C. Personality testing may identify applicants who will become successful in general surgery residency. J Surg Res. 2019;233:240-248.

5. Buckley K, Karr S, Nisly S A, Kelley K. Evaluation of a mock interview session on residency interview skills. Curr Pharm Teach Learn. 2018;10:511-516. 